\title{
Effect of different herbals feed additives on body weight gain and dressing percentage of Giriraja poultry birds
}

\author{
ABDUL HAFIZ PAKRAWAN, R.R. SHELKE, S. D. CHAVAN, P. A. KAHATE AND R.D.WALKE
}

\begin{abstract}
The present investigation entitled "effect of different herbals feed additives on body weight gain and dressing percentage of Giriraja poultry birds" was carried out to assess the effect of feeding coriander and Tulsi seed powder on body weight gain and dressing percentage, during 2016-17 at Department of Animal Husbandry and Dairy Science, Dr. Panjabrao Deshmukh Krishi Vidyapeeth, Akola. 125 chicks of day-old straight run commercial Giriraja breed were procured from Govt. hatchery. They were randomly and equally distributed in to five dietary treatments consisted of on basal control ( $\left.\mathrm{T}_{1}\right)$ (untreated group), supplemented with one per cent coriander seed powder $\left(\mathrm{T}_{2}\right) 2$ per cent coriander seed powder $\left(\mathrm{T}_{3}\right), 1$ per cent Tulsi seed powder $\left(\mathrm{T}_{4}\right)$ and 2 per cent Tulsi seed powder $\left(\mathrm{T}_{5}\right)$. The significant difference in weekly body weight gain was found only on third week. But in cumulative live body weight gain the significant difference was observed from second week on ward. The trend of significantly better growth and gain in cumulative was recorded in $\mathrm{T}_{1}(1063.42), \mathrm{T}_{2}(1157.78), \mathrm{T}_{3}(1200.56), \mathrm{T}_{4}(1182.16)$ and $\mathrm{T}_{5}$ (1229.15) groups during second to seventh week. Average weekly cumulative live body weight gain as treatment mean was calculated as $512.99,548.75,572.54,564.27$ and 585.75 for treatment $\mathrm{T}_{1}, \mathrm{~T}_{2}, \mathrm{~T}_{3}, \mathrm{~T}_{4}$ and $\mathrm{T}_{5}$, respectively. The average dressing percentage among the different treatment groups was recorded as 63.36, 65.39, 67.78,66.37 and 68.32 per cent for treatment $\mathrm{T}_{1}, \mathrm{~T}_{2}$. $\mathrm{T}_{3}, \mathrm{~T}_{4}$ and $\mathrm{T}_{5}$, respected. The effect of coriander and Tulsi seed powder feeding on dressing percentage was found to be beneficial and positively effect on dressing percentage of poultry birds. Supplementation of 2 per cent Tulsi seed powder was found more beneficial to live body weight gain and dressing percentage of Giriraja poultry birds.
\end{abstract}

KEY WORDS : Giriraja, Herbal, Body coriander, Tulsi seed powder, Weight gain, Dressing percentage

HOW TO CITE THIS PAPER : Pakrawan, Abdul Hafiz, Shelke, R.R., Chavan, S. D., Kahate, P.A. and Walke, R.D. (2017). Effect of different herbals feed additives on body weight gain and dressing percentage of Giriraja poultry birds. Res. J. Animal Hus. \& Dairy Sci., 8(1) : 8-12 : DOI: 10.15740/HAS/RJAHDS/8.1/8-12. 